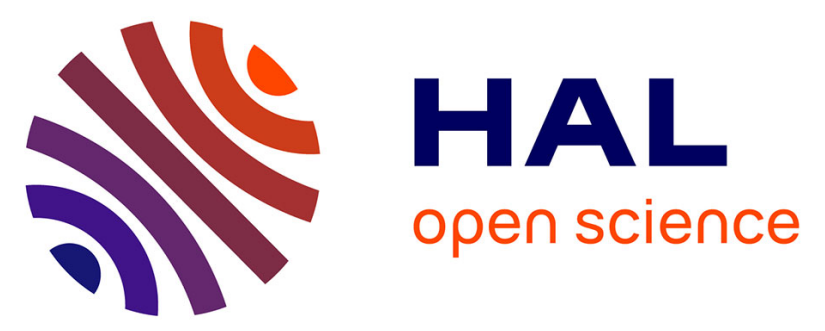

\title{
Isothermal aging and shear creep behavior of a novel lead-free solder joint with small additions of $\mathrm{Bi}, \mathrm{Sb}$ and $\mathrm{Ni}$
}

\author{
Q.B. Tao, L. Benabou, T.A. Nguyen Van, H. Nguyen-Xuan
}

\section{- To cite this version:}

Q.B. Tao, L. Benabou, T.A. Nguyen Van, H. Nguyen-Xuan. Isothermal aging and shear creep behavior of a novel lead-free solder joint with small additions of $\mathrm{Bi}, \mathrm{Sb}$ and $\mathrm{Ni}$. Journal of Alloys and Compounds, 2019, 789, pp.183 - 192. 10.1016/j.jallcom.2019.02.316 . hal-03484777

\section{HAL Id: hal-03484777 \\ https://hal.science/hal-03484777}

Submitted on 20 Dec 2021

HAL is a multi-disciplinary open access archive for the deposit and dissemination of scientific research documents, whether they are published or not. The documents may come from teaching and research institutions in France or abroad, or from public or private research centers.
L'archive ouverte pluridisciplinaire HAL, est destinée au dépôt et à la diffusion de documents scientifiques de niveau recherche, publiés ou non, émanant des établissements d'enseignement et de recherche français ou étrangers, des laboratoires publics ou privés.

\section{(ㄷ)(1) $\$$}

Distributed under a Creative Commons Attribution - NonCommercial| 4.0 International 


\section{Effects of Isothermal Aging on Microstructure and Shear Creep \\ Behaviour of A Novel Lead-free Solder Joint With Small Additions of Bi, Sb and Ni}

Q.B. Tao ${ }^{1}$, L. Benabou ${ }^{2, *}$, T.A. Nguyen $\operatorname{Van}^{1}$, H. Nguyen-Xuan ${ }^{3}$

1: Department of Mechanical Engineering, University of Science and Technology, The University of Danang, Viet Nam

2: LISV, Université de Versailles Saint-Quentin-en-Yvelines, Paris Saclay University, France

3: CIRTech Institute, Ho Chi Minh City University of Technology (HUTECH), Ho Chi Minh City, Viet Nam

*Corresponding author:

E-mail addresses: lahouari.benabou@uvsq.fr (L. Benabou), tqbang@dut.udn.vn (Q.B. Tao) 


\begin{abstract}
In this paper, we investigate the effects of isothermal aging on the microstructure and creep properties of a novel lead-free SAC387-3Bi-1.5Sb-0.15Ni (InnoLot)/Cu solder joints. Single-lap shear solder joints of the InnoLot solder were aged up to 1 year at $100^{\circ} \mathrm{C}$, and then loaded to failure in shear creep tests under different applied shear stresses and testing temperatures. The findings show that both aging time and temperature lead to the global increase of the interfacial IMC thickness significantly, but the growth of the Sn-rich IMC layer during aging remains limited in comparison with other solder materials due to the $\mathrm{Ni}$ content. In addition, shear creep tests reveal that the shear creep strength of the aged solder joint decreases initially before remaining dramatically stable in the long term. In terms of failure modes, shear creep tests at room and elevated temperatures show distinct rupture features. While rupture within the bulk solder happens at higher temperatures, rupture through the interface occurs at lower temperatures. When the specimens are exposed to isothermal aging, creep deformation becomes more predominant. The aged microstructure exhibits a brittle-to-ductile transition with occurrence of intergranular fracture due to the dynamic recrystallization inside the solder matrix. It is observed that the mechanical factor is of first-order importance in the formation of the new grain structure of the solder.
\end{abstract}

Keywords: Lead-free solder; Solder joint; Creep behavior; Intermetallic; Fracture solder joint 


\section{Introduction}

The global concern about the environmental impact of toxic lead-based solders in consumer electronics has motivated development of lead-free solder alloys [1]. As known, $\mathrm{Pb}$-containing solder alloys have been eliminated from electronic packaging in many industrial companies and countries. Indeed, the European Union issued the Waste of Electrical and Electronic Equipment aiming to prohibit the use of $\mathrm{Sn}-\mathrm{Pb}$ solders by year 2006. Following that, the development of lead-free solders, substituting Pb-based solder alloys used in microelectronic packaging processes, has become an important field of both academic and industrial research. It is fact that new developed lead-free solders should not only have good process performance but also have better mechanical behaviors.

Up to date, some studies have proved that lead-free solder alloys have many advantages over Pb-based solders. They are more environment-friendly and have superior interfacial properties, high creep resistance, low coarsening rate, etc. [2-7]. Nowadays, the $\mathrm{Sn}-\mathrm{Ag}-\mathrm{Cu}$ (SAC) solders are the most used in electronic packaging. In recent years, a huge number of lead-free solders have been reported. However, they exist still some drawbacks that can limit the adoption of these solders to certain applications, especially for devices which work at high operating temperatures. Therefore, new third generation lead-free solders are being targeted for use under these harsh environments requiring resistance to both thermal and mechanical constraints. Indeed, one of the strategies that manufacturers have chosen to improve the reliability of lead-free solder joints is to add minor alloying to lead-free solders [8-14]. The most common alloying elements are $\mathrm{Ni}, \mathrm{Bi}, \mathrm{Sb}, \mathrm{Zn}, \mathrm{Al}$, and $\mathrm{Cu}$. Among these metal additives, $\mathrm{Ni}, \mathrm{Bi}$ and $\mathrm{Sb}$ are extensively used to create novel solder alloys which are suited well for use in some demanding services. The advantages of these alloys have been separately found in the literature $[9,11,15-16]$. Among lead-free solder alloy candidates, the novel lead-free solder alloy based on SAC387 solder (comprised of Sn with 3.8\% Ag, 0.7\% $\mathrm{Cu}, 3.0 \% \mathrm{Bi}, 0.2 \% \mathrm{Ni}$ and $1.54 \% \mathrm{Sb}$ ), namely InnoLot, is largely used in the electronic assemblies, especially in automobiles. This alloy has great potential to outperform not only existing SAC solder alloy but also to surpass $\mathrm{Sn}-\mathrm{Pb}$ as well in long-term reliability. The alloy is targeted for use in harsh environments and have been designed to improve toughness of interfacial intermetallic layers, and to provide solid solution strengthening to compensate for the loss of strength once the $\mathrm{Ag}_{3} \mathrm{Sn}$ particles coarsen $[17,18]$.

Since the microelectronic industry has achieved rapid development in recent year, the importance of soldering at high temperatures and that of reliability of devices are increasing 
as well. In electronic packaging assemblies, electronic interconnects serve both electronic and mechanical functions between the electronic components and printed circuit boards. However, they are the easiest way to fail in the whole package. When a microelectronic assembly is in operation at high homologous temperatures exceeding $0.5 T_{m}$ ( $T_{m}$ : melting temperature) [19], stresses caused by temperature gradients and fluctuations can lead to viscous creep flow of the solder joint, resulting in joint failure. Therefore, it is necessary to gain insight into the creep behavior of solder joint in order to increase its reliability. Indeed, the creep behavior of lead-free solders containing alloys has been studied by many researchers. Xiao et al. [20] showed that added rare earths of $60 \mathrm{wt} \% \mathrm{Ce}$ and $30 \mathrm{wt} \% \mathrm{La}$ into SAC387 solder can measurably increase the creep-fatigue rupture lifetime of the SAC solder joint. The creep rupture times for SAC305-xBi solder joint with up to $4 \mathrm{wt} \%$ of $\mathrm{Bi}$ are longer than that for SAC305, which shows that the addition of Bi can enhance the creep behavior of the solder joints [21]. Also, an increase in creep resistance and the total fracture time is observed in SAC-Ni with addition of Ni to SAC solder alloys [22].

Furthermore, during actual working conditions, the soldered joints are subjected to aging conditions such as the continuous use of electronic equipment, temperature storage, and power on-off cycles. The effect of isothermal aging on creep behavior and microstructural changes of solder joint have been investigated in the literature [17, 23-28]. Effect of isothermal aging on the secondary creep response of SAC305 and SAC405 lead-free solders was studied by Ma et al. [28]. They found that isothermal aging for longer durations was observed to drastically reduce the secondary creep resistance of the two solder alloys. Similar observations have been also reported by Xiao et al. [29] for SAC396 and Sn37Pb alloys, which were aged at $180^{\circ} \mathrm{C}$, showing that aging decreases the hardness of solder joints and makes them more susceptible to creep deformation and rupture.

Thus, far many studies have been reported on the creep behaviors of the solders, some creep parameters such as creep stress exponents and activation energies of the solders, were obtained. However, to our knowledge, only a recently published study has focused on the microstructural evolution of the quite recently introduced InnoLot solder joint under isothermal aging [17]. It seems usefully to further study the creep behaviors of solder alloys with additions of $\mathrm{Bi}, \mathrm{Ni}$, and $\mathrm{Sb}$, that is the case of the InnoLot solder alloy.

The discussion above indicates that a comprehensive, intuitionistic understanding of the creep behavior and the relationship between microstructure evolution and mechanical aging effects on the novel solder joint are necessary. The present study deals with more aspects of the InnoLot creep and aging behavior with mechanical and microstructural analyses 
performed. A large number of creep tests were carried out at various stress levels from 5.89 to $25.25 \mathrm{MPa}$, over a wide temperature range from $25^{\circ}$ to $125^{\circ} \mathrm{C}$ and at different aging times at $100^{\circ} \mathrm{C}$ up to 1 year. The Scanning Electronic Microscope (SEM) was used to conduct the experiments and to observe the microstructure evolution of the solder joint under different conditions. The effect of testing conditions and aging time on microstructure and creep behavior of the solder joint was analyzed in this study.

\section{Experimental procedure}

\subsection{Sample preparation}

The SAC387-3Bi-1.5Sb-0.15Ni /Cu solder joints, hereafter named as InnoLot solder joints, were prepared using a commercial solder sheet and copper strips with a purity of 99.9\% as substrates. A detailed method to fabricate a miniature single lap-shear specimen that mimics as closely as possible the actual solder joints used in automobile and microelectronic devices can be also found in prior studies [30-34]. Briefly, lap shear specimens were prepared by connecting two copper $(\mathrm{Cu})$ substrates with the InnoLot solder foil. Due to the larger stiffness of the copper substrates, the deformation is assumed to occur mainly in the solder joint. The $\mathrm{Cu}$ rod was firstly spark cut into small blocks, then the surfaces of soldering were ground, electrolytically polished, and cleaned consecutively with $50 \%$ nitric acid and acetone, before being dispersed by solder flux on the polished areas. After that the solder sheets, which are cut with the right dimensions, were sandwiched between the two $\mathrm{Cu}$ substrates. Then, the prepared specimens were kept by $\mathrm{Al}$ fixture and put in an oven to undergo a specific reflow thermal profile, as used in the industry [35]. The reflow profile is shown in Fig. 1.

\subsection{Thermal aging and testing experimental plan}

After soldering, some of the as-soldered joints were thermally aged for up to 12 months in an oven under the aging temperature of $100^{\circ} \mathrm{C}$. These aging specimens will be tested at room temperature under different applied shear stresses. The aging temperature of $100 \mathrm{C}$ was selected with respect to the average level of temperature occurring during the service of the real devices. This aging imposed on the specimens simulates the aging of real devices in a natural accelerated way. It makes it possible to study the microstructural effects on the mechanical properties.

The shear creep tests were carried out on a micro-tensile test system [31]. The shear applied stress levels for creep tests were taken as increasing proportions of the Ultimate 
Tensile Stress (UTS) of the solder joints measured in earlier studies [30-32]. The list of all shear creep tests conducted in this study are shown in Table 1. The tensile loading was quickly applied to the specimen to the designed stress level and then, stress was held during the whole creep test. The creep tests were performed at three temperatures, room $\left(25^{\circ} \mathrm{C}\right)$, $75^{\circ} \mathrm{C}$, and $125^{\circ} \mathrm{C}$, representing homologous temperature of $0.61,0.71$, and $0.81\left(\mathrm{~T} / \mathrm{T}_{\mathrm{m}}\right)$, respectively. At each test temperature, applied shear stresses ranging from $5.89 \mathrm{MPa}$ to 25.25 MPa were used. During the deformation process, the dynamic strain and time data were recorded.

In order to reduce the experimental errors attached to the measurements and to get the most reliable results, at least three samples were examined under each condition to get averaged values for properties. Figure 2 shows an actual lap-shear joint specimen used for this study.

\section{Results and Discussion}

\subsection{Viscoplastic creep curves}

Figure 3 presents the typical creep strain-time curve of the InnoLot solder joint at $25^{\circ} \mathrm{C}$ under applied shear stress of 25.25 MPa. It can be seen that the creep curve consists of three stages: firstly, a short primary creep stage, followed by a long steady-state stage and finally a tertiary creep stage characterized by an accelerating creep strain rate that leads to rupture of the joint. Attention was focused on the secondary stage since it dominates the creep rupture life of the solder. The secondary regime is the longest in duration and thus represents most of the solder lifetime. Based on the creep curve, the secondary creep strain rate can be determined for different time periods by taking the derivative of the creep strain with creep time. The minimum rate was taken as the creep strain rate for the secondary stage.

Figure 4 shows the typical set of creep curves of the InnoLot solder joints at temperature of $25^{\circ} \mathrm{C}$ for different applied stress levels. It can be seen that the creep deformation increases with increasing stress levels. Higher stresses will accelerate the movement of dislocations, which includes dislocation gliding and climb. Higher stresses will also induce greater grain boundary sliding. Dislocation gliding and grain boundary sliding are the major creep mechanisms for creep deformation.

Figure 5 shows a set of typical creep curves at various temperatures for same stress level of $11.875 \mathrm{MPa}$, indicating that higher temperatures induce more intense creep deformation in solder alloys. Creep deformation is diffusion controlled, and so a higher temperature will lead 
to a higher diffusion rate and a higher creep rate. It is obviously apparent that both the creep strain rate and rupture time are sensitive to the applied stress and the temperature.

Furthermore, Figure 6 shows the steady-state shear creep rate which is plotted in for various aging times. It can be seen that the increase in the steady-state creep rate is extremely large (several orders of magnitude) during the first 30 days, so the resistance to creep deformation dramatically declines during this quite short aging period. Thereafter, the creep rate remains remarkably constant, even over periods as long as a year. In addition, reduction of the shear modulus $\mathrm{G}$ of InnoLot/Cu solder joints after reflowing and isothermal aging at $100^{\circ} \mathrm{C}$ is shown in Figure 7, where the shear modulus of the solder joints is seen to decrease with increasing aging time after isothermal aging processing.

\subsection{Microstructural investigations}

\subsubsection{Bulk and as-reflowed joint microstructures}

After the reflow process, all reflowed samples were checked and measured under optical microscope and SEM for ensuring the right dimensions and observing the microstructure of the joints, respectively. Now, the structures of bulk and as-reflowed InnoLot solder joint are evaluated by using SEM analyses as indicates in Figure 8. In the case of bulk specimen, it can be found that the microstructure of the InnoLot solder is composed by $\beta-S n$ matrix phase (including Bi particles in white color), and IMC grains (see Fig. 8a). Since there is a small amount of supplemented $\mathrm{Sb}, \mathrm{Ni}$, and $\mathrm{Bi}$ elements in SAC387-3Bi-1.5Sb-0.15Ni, the two IMCs were found in this solder alloy are $\mathrm{Ag}_{3}(\mathrm{Sn}, \mathrm{Sb})$ and $(\mathrm{Cu}, \mathrm{Ni})_{6} \mathrm{Sn}_{5}$. The particles are sparsely distributed within the eutectic regions [30,31]. The advantages of these addition atoms on the mechanical properties as well as the microstructure have been investigated in early studies $[30,31,33,34]$. For solder joint specimens as shown in Fig. 8b, due to the atomic interdiffusion between the molten solder and the $\mathrm{Cu}$ substrates at the interfaces, specific IMC particles are formed during the reflowing process. Indeed, a $(\mathrm{Cu}, \mathrm{Ni})_{6} \mathrm{Sn}_{5}$ layer is formed in the early stage of the soldering process. Then from the bulk solder, the layer grows by consuming the $\mathrm{Sn}, \mathrm{Cu}$, and $\mathrm{Ni}$ atoms to forming some long dendrites. When the dendrites become too long, they move away from the IMC interfacial layer for forming some intermetallic phases that diffuse inside the bulk solder joint. Also, a Cu-rich intermetallic planar layer, $(\mathrm{Cu}, \mathrm{Ni})_{3} \mathrm{Sn}$, is formed at the interface between the $\mathrm{Cu}$ substrate and the IMC layer. 


\subsubsection{Effect of temperature}

Figure 9 shows the SEM cross-sectional images at different positions of the joint specimen after shear creep tests at room temperature $\left(25^{\circ} \mathrm{C}\right)$ and $125^{\circ} \mathrm{C}$ under the applied shear stress of $18.75 \mathrm{MPa}$. Compared with the microstructures before shear creep testing (see Fig. $8 b)$, the $\mathrm{Ag}_{3}(\mathrm{Sn}, \mathrm{Sb})$ phase has become interdendritic and coarser. In addition, the $\beta-S n$ phases have undergone an axial growth with long orientated phases which were activated by the mechanical energy applied during the shear creep test.

Figure 10 shows a diagram of the failure patterns of the InnoLot solder joints according to the level of temperature (room temperature and $125^{\circ} \mathrm{C}$ in our case). For the test at room temperature, it can be understood that the fragile rupture path occurs within the IMC layer. For the test at the higher temperature, the fragile rupture starts in the IMC layer and is then accompanied by local ductile rupture within bulk solder. Both tests at room and $125^{\circ} \mathrm{C}$ have similar rupture initiation within the IMC layers, which is caused by the their brittleness and may be favored by the presence of Kirkendall voids in these IMC layers. For the rupture that happened inside the bulk solder joint, this seems to occur in the area where a microstructural transformation has occurred, which is explained as follows. The fine interdendritic $\mathrm{Ag}_{3}(\mathrm{Sn}, \mathrm{Sb})$ phases coalesce to make larger $\mathrm{Ag}_{3}(\mathrm{Sn}, \mathrm{Sb})$ globular phases. With increased temperature, a growth in the size of $\beta-S n$ phase and further coarsening of the $\mathrm{Ag}_{3}(\mathrm{Sn}, \mathrm{Sb})$ particles are observed compared with those in the shear creep test at room temperature. It is also found that with increasing testing temperature, the number of cracks on the surface of the specimen increases. Thus, these factors lead to a loss of creep resistance in the InnoLot solder joint.

\subsubsection{Effect of isothermal aging}

In order to assess the effects of isothermal aging on the microstructure, samples of the InnoLot solder were aged at temperature of $100^{\circ} \mathrm{C}$ for different aging times as discussed above and some fracture specimens were examined by SEM as mentioned before. Figure 11 represents the SEM images after the shear creep tests with applied stress of $18.75 \mathrm{MPa}$ at $25^{\circ} \mathrm{C}$ for 0 day to 365 days aging at $100^{\circ} \mathrm{C}$. It can be seen that the intermetallic phases under these conditions are dispersed among the Sn extended phase and neither dendrites nor 
interdendritic precipitations are observed. However, there are some differences between the analyzed samples. As known, the morphology and size of the various compounds are influenced by process parameters such as the imposed reflow parameters, but also the postreflow thermal aging [17]. In this study, when increasing aging time, the average grain size of the intermetallic phases increases while their roughness decreases. The global growth of the IMC, consisting mainly of the $(\mathrm{Cu}, \mathrm{Ni})_{6} \mathrm{Sn}_{5}$ phase, is known to have a direct impact on the failure mode in the solder joint by lowering its fracture toughness [36]. Indeed, when the aging time is increased from 1 month to 2 months, the size of IMC phases is increased by a factor of three, $\sim 1 \mu \mathrm{m}$ compared with $\sim 3 \mu \mathrm{m}$ for the $\mathrm{Ag}_{3} \mathrm{Sn}$ phases. As for roughness of the IMC layer, it decreases from $078 \mu \mathrm{m}$ just after reflowed to $0.54 \mu \mathrm{m}$ and $0.51 \mu \mathrm{m}$ for 1 - and 2 month isothermal aging, respectively. While the overall IMC thickness is promoted by aging time, the roughness of $(\mathrm{Cu}, \mathrm{Ni})_{6} \mathrm{Sn}_{5}$ phase is reduced, making the IMC layer smoother overtime. Also, the $(\mathrm{Cu}, \mathrm{Ni})_{6} \mathrm{Sn}_{5}$ layer in the specimen aged for 1 year exhibits multiple voids, as well as big cavities at the interface with the Sn matrix (see Fig. 11c). It is postulated in this case that the strong growth of the $(\mathrm{Cu}, \mathrm{Ni})_{6} \mathrm{Sn}_{5}$ layer during extended aging periods consumes the low amount of $\mathrm{Cu}$ contained in the solder, resulting in such cavities. It is also known that the formation of the $\eta$-phase is accompanied by a significant volume contraction [37], which may cause inner stresses and generate the large voids at the solder/(Cu,Ni) ${ }_{6} \mathrm{Sn}_{5}$ interface.

With regards to fracture patterns after isothermal aging, Figure 12 shows intergranular cracks after a shear creep test of a 2-month isothermal aged specimen. Fragile rupture near the IMC/solder interface occurs in tandem with ductile rupture along the Sn grain boundaries inside the bulk solder. Firstly, the IMC smoothens and becomes less scalloped with aging, which promotes to a certain extent IMC/solder interfacial de-cohesion rather than rupture inside the IMC grains as was the case with the as-reflowed specimen. Secondly, it appears that aging of the microstructure is accelerated in the most stressed regions of the joint where dynamic recrystallization occurs. In terms of crack propagation inside the bulk solder, crack propagates from the right side (yellow arrow) bifurcated into many cracks at the end of the red dotted arrow pointed area. On the other hand, cracking happens in the region near the interface, due to the presence of large voids at the interfaces. It can be explained by the fact that the energy needed for the crack to propagate through the IMCs is much higher than that needed for its propagation in the softer Sn-rich phase through the grain boundaries or at the interface with the IMC. Additionally, accumulation of deformation in the solder matrix occurs in the area close to the IMC layer and the crack. Likewise, the deformation may due to 
the grain boundary sliding. This creep deformation mechanism is very important in the solder alloy. Creep cavities are also detected in the highly deformed areas. The cavities reduce the load-bearing area, which inevitably accelerates the failure process.

For the case of the 1-year aged specimen as shown in Figure 13, the Sn grains grow and their boundaries become clearly visible, especially near the joining interface where the stresses are relatively important. Another close view of the interface between the IMC layer and the solder bulk (see Fig. 13b) reveals distinctly the presence of some Sn grains in this region of high stresses (with grain size around 2-3 $\mu \mathrm{m}$ ). Even if the IMC layer is less rough with aging time, it still provides sites of strain concentration due not only to some remaining scallop tips but also to the elastoplastic misfit between the solder and the IMC materials. After the crack develops into the bulk region, grains are present all along the edges of the rupture path. In this case, the stress concentration effect accompanying the advancing crack tip region is responsible for the dynamic recrystallization of the matrix. Conversely, the recrystallized microstructure offers the crack an easy path through the grain boundaries for its propagation. This implies that the two mechanisms (recrystallization and cracking) come together and support one another and that the microstructural evolution has a direct impact on the type of failure mode triggered in the solder joint with a brittle-to-ductile transition in the fracture behavior (from IMC interface decohesion to intergranular cracking). The ductile rupture is also manifested in substantial plastic deformation inside the non-recrystallized $\mathrm{Sn}$ phases prior to intergranular crack propagation. The isothermal aging conditions indeed cause the Sn phases to aggregate and extend, which is expected to remove barriers to dislocation movement, and thus to increase ductility of the solder material.

\section{Conclusions}

In this study, testing conditions, aging effects and creep behavior along with microstructure evolutions in novel lead-free InnoLot solder have been investigated. Based on the experimental results, the following major conclusions can be summarized:

(1) Both aging time and temperature increase interfacial IMC thickness significantly, the growth of the IMC layer during aging exhibited a diffusion-type relationship.

(2) Shear creep tests results reveal that as-reflowed solder joint has better shear creep strength than the aged solder joints. The shear creep strength of the aged solder joints 
decreases with increasing aging time. It leads to increasing of the IMC thickness and decreasing of the roughness.

(3) The shear creep tests at room and higher temperatures have similar rupture area within IMC layers and it is explained by the presence of Kirkendall voiding at the interfaces. However, at elevated temperatures, the fragile rupture was started in IMC layer and followed by local ductile rupture within the bulk solder material. This seems to occur in the area where microstructural transformation occurs.

(4) When specimens are exposed to isothermal aging, the creep is much faster than nonaged specimens. After 30 days, the steady-state shear creep rate was stable. Additionally, the aged microstructures exhibit a brittle-to-ductile transition with occurrence of intergranular fracture due to the dynamic recrystallization inside the solder matrix. It appears that the mechanical factor is of first-order importance in the formation of the new grain structure of the solder. 


\section{Acknowledgments}

This research was supported by the Vietnam National Foundation for Science and Technology Development (NAFOSTED) under grant number 107.01-2018.32. The authors would like to thank Dr. K.L. Tan and Dr. J.M. Morelle from VALEO company, France for providing us with the solder materials. 


\section{References}

[1] J.S. HWang, Implementing lead-free electronics, McGraw-Hill, New York 2004.

[2] J. Keller, D. Baither, U. Wilke, G. Schmitz, Mechanical properties of Pb-free SnAg solder joints, Acta Mater. 59(7) (2011) 2731-2741.

[3] A.A. El-Daly, A.M. El-Taher, Evolution of thermal property and creep resistance of Ni and Zn-doped Sn-2.0Ag-0.5Cu lead-free solders, Mater. Des. 51 (2013) 789-796.

[4] F. Ochoa, J.J. Williams, N. Chawla, Effects of cooling rate on the microstructure and tensile behavior of a Sn-3.5wt\%Ag solder, J. Electron. Mater. 32(12) (2003) 1414-1420.

[5] S.J. M. McCormack, G.W. Kammlott, and H.S. Chen, New Pb-free solder alloy with superior mechanical properties, Appl. Phys. Lett. 63 (1993) 15.

[6] Y. Kariya, M. Otsuka, Effect of bismuth on the isothermal fatigue properties of Sn3.5mass\%Ag solder alloy, J. Electron. Mater. 27(7) (1998) 866-870.

[7] W.J. Plumbridge, Solders in electronics, J. Mater. Sci. 31(10) (1996) 2501-2514.

[8] L. Zhang, S.B. Xue, L.L. Gao, G. Zeng, Z. Sheng, Y. Chen, S.L. Yu, Effects of rare earths on properties and microstructures of lead-free solder alloys, J. Mater. Sci.: Mater. Electron. $20(8)$ (2009) 685-694.

[9] A.E. Hammad, Evolution of microstructure, thermal and creep properties of Ni-doped $\mathrm{Sn}-$ $0.5 \mathrm{Ag}-0.7 \mathrm{Cu}$ low-Ag solder alloys for electronic applications, Mater. Des. 52 (2013) 663670 .

[10] M.H. Mahdavifard, M.F.M. Sabri, D.A. Shnawah, S.M. Said, I.A. Badruddin, S. Rozali, The effect of iron and bismuth addition on the microstructural, mechanical, and thermal properties of $\mathrm{Sn}-1 \mathrm{Ag}-0.5 \mathrm{Cu}$ solder alloy, Microelectron. Reliab. 55(9-10) (2015) 18861890.

[11] A.A. El-Daly, A.E. Hammad, A. Fawzy, D. A. Nasrallh, Microstructure, mechanical properties, and deformation behavior of $\mathrm{Sn}-1.0 \mathrm{Ag}-0.5 \mathrm{Cu}$ solder after $\mathrm{Ni}$ and $\mathrm{Sb}$ additions, Mater. Des. 43 (2013) 40-49.

[12] A.A. El-Daly, A.M. El-Taher, Improved strength of $\mathrm{Ni}$ and $\mathrm{Zn}$-doped $\mathrm{Sn}-2.0 \mathrm{Ag}-0.5 \mathrm{Cu}$ lead-free solder alloys under controlled processing parameters, Mater. Des. 47 (2013) 607614.

[13] D.Q. Yu, J. Zhao, L. Wang, Improvement on the microstructure stability, mechanical and wetting properties of $\mathrm{Sn}-\mathrm{Ag}-\mathrm{Cu}$ lead-free solder with the addition of rare earth elements, J. Alloys Compd. 376(1-2) (2004) 170-175. 
[14] F. Cheng, H. Nishikawa, T. Takemoto, Microstructural and mechanical properties of SnAg-Cu lead-free solders with minor addition of Ni and/or Co, J. Mater. Sci. 43(10) (2008) 3643-3648.

[15] A.E. Hammad, Investigation of microstructure and mechanical properties of novel Sn$0.5 \mathrm{Ag}-0.7 \mathrm{Cu}$ solders containing small amount of Ni, Mater. Des. 50 (2013) 108-116.

[16] B.L.C. G.Y. Li, X.Q. Shi, S.C.K. Wong, and Z.F. Wang, Effects of Sb addition on tensile strength of Sn-3.5Ag-0.7Cu solder alloy joint, Thin Solid Films 504 (2006) 421-425.

[17] L. Benabou, L. Vivet, Q.B. Tao, and N.H. Tran, Microstructural effects of isothermal aging on a doped SAC solder alloy, Inter. J.Mater. Res. 109 (2018) 76-82.

[18] M.N. Collins, E. Dalton, J. Punch, Microstructural influences on thermomechanical fatigue behaviour of third generation high Ag content Pb-Free solder alloys, J. Alloy. Compd. 688 (2016) 164-170.

[19] I. Dutta, A constitutive model for creep of lead-free solders undergoing strain-enhance microstrucral coarsening: A first report, J. Electro. Mater. 32 (2003) 201-207.

[20] W.M. Xiao, Y.W. Shi, G.C. Xu, et al., Effect of rare earth on mechanical creep-fatigue property of SnAgCu solder joint, J. Alloy. Compd. 472 (2009) 198-202.

[21] D. Witkin, Creep behavior of Bi-containing lead-free solder alloys, J. Electro. Mater. 41 (2012) 190-203.

[22] A.E. Hammad, Enhancing the ductility and mechanical behavior of Sn-1.0A-0.5Cu leadfree solder by adding trace amount of elements Ni and Sb, Microelectro. Reliab. 87 (2018) 133-141.

[23] G. Chen, H. Peng, V.V. Silberschmidt, et al., Performance of Sn-3.0Ag-0.5Cu composite solder with TiC reinforcement: Physical properties, solderability and microstructural evolution under isothermal ageing, J. Alloy. Compd. 685 (2016) 680-689.

[24] X. Hu, Y. Li, Y. Liu, Y. Liu, and Z. Min, Microstructure and shear strength of $\mathrm{Sn} 37 \mathrm{~Pb} / \mathrm{Cu}$ solder joints subjected to isothermal aging, Microelectro. Reliab. 54 (2014) 15751582.

[25] M.F.M. Sabri, D.A. Shnawah, I.A. Badruddin, S.B.M. Said, Effects of aging on Sn-1Ag$0.5 \mathrm{Cu}$ solder alloys containing $0.1 \mathrm{wt} . \%$ and $0.5 \mathrm{wt} . \%$ Al, J. Alloy. Compd. 582 (2014), $437-$ 446.

[26] G. Chen, H. Peng, V.V. Silberschmidt, Y.C. Chan, C. Liu, F. Wu, Performance of Sn3.0Ag-0.5Cu composite solder with TiC reinforcement: Physical properties, solderability and microstructural evolution under isothermal ageing, J. Alloy. Compd. 685 (2016), 680-689. 
[27] M.N. Collins, E. Dalton, J. Punch, Microstructural influences on thermomechanical fatigue behaviour of third generation high Ag content Pb-Free solder alloys, J. Alloy. Compd. 688 (2016), 164-170.

[28] H. Ma, J.C. Suhling, Y. Zhang, P. Lall, and M.J. Bozack, The influence of elavated temperature aging on reliability of lead free solde joints, Procee. $57^{\text {th }}$ Electro. Compo. Tech. Conf., 2007.

[29] Q. Xiao, L. Nguyen, W.D. Armstrong, Aging and creep behavior of Sn3.9Ag0.6Cu solder alloy, Procee. 54 ${ }^{\text {th }}$ Electro. Compo. Tech. Conf., pp. 1325-1332, 2004.

[30] Q.B. Tao, L. Benabou, L. Vivet, V.N. Le, and F.B. Ouezdou, Effect of Ni and Sb additions and testing conditions on the mechanical properties and micrsotructures of lead-free solder joints, Mater. Sci. Eng.: A 669 (2016) 403-416.

[31] Q.B. Tao, L. Benabou, L. Vivet, K.L. Tan, J.M. Morelle, V.N. Le, and F.B. Ouezdou, A design of a new miniature device for solder joints' mechanical properties evaluation, Procee. Inst. Mech. Eng., Part C: J. Mech. Eng. Sci. 231 (2017) 3818-3830.

[32] Q.B. Tao, L. Benabou, K.L. Tan, J.M. Morelle, and F.B. Ouezdou, Creep behavior of Innolot solder alloy using small lap-shear specimens, Procee. $17^{\text {th }}$ Electro. Packag. Tech. Conf. (EPTC), 2015.

[33] V.N. Le, L. Benabou, V. Etgens, and Q.B. Tao, Finite element analysis of the effect of process-induced voids on the fatigue lifetime of a lead-free solder joint under thermal cycling, Microelectron. Reliab. 65 (2016) 243-254.

[34] V.N. Le, L. Benabou, V. Etgens, and Q.B. Tao, Modelling of intergranular thermal fatigue cracking of a lead-free solder joint in a power electronic module, Inter. J. Solids Struct. 106 (2017) 1-12.

[35] Valeo company, Smart Technology for Smarter Cars. https://www.valeo.com/en/

[36] P. Kumar, Z. Huang, I. Dutta, R. Sidhu, M. Renavikar, and R. Mahajan, Fracture of Sn$\mathrm{Ag}-\mathrm{Cu}$ solder joints on $\mathrm{Cu}$ substratees. II: Fracture mechanism map, J. Electro. Mater. 41 (2012) 412-424.

[37] Y. Yang, H. Lu, C. Yu, and Y. Li, Void formation at the interface in Sn/Cu solder joints, Microelectron. Reliab. 51 (2011) 2314-2318. 


\section{Figure captions}

Fig. 1. Reflow process for the InnoLot solder joints: (a) recommended reflow, (b) applied reflow profiles.

Fig. 2. Actual lap-shear solder joint specimen.

Fig. 3. A typical creep curve of the InnoLot solder joint at $25^{\circ} \mathrm{C}$ and applied stress of 25.25 MPa.

Fig. 4. The typical set of creep curves of the InnoLot solder joints at temperature of $25^{\circ} \mathrm{C}$ for different applied stress levels.

Fig. 5. The typical set of creep curves at various temperatures for the same stress level of 11.875 MPa.

Fig. 6. The steady-state shear creep strain rate with respect to aging time.

Fig. 7. The shear modulus of the InnoLot/Cu solder joints with respect to aging time.

Fig. 8. SEM cross-section images of bulk (a), and as-reflowed InnoLot joint specimen (b).

Fig. 9. Cross sectional micrographs of the interfacial IMC layers and inside bulk solder subjected to creep tests under $18.75 \mathrm{MPa}$ at $25^{\circ} \mathrm{C}$ and $125^{\circ} \mathrm{C}$ : inside the bulk solder joint (a1, $\mathrm{a} 2)$, and at the lower IMC layer (b1, b2).

Fig. 10. The failure modes of solder joints at low and high temperatures: (a) $25^{\circ} \mathrm{C}$, (b) $125^{\circ} \mathrm{C}$.

Fig. 11. The microstructure after aging of InnoLot solder joint for a temperature at $100^{\circ} \mathrm{C}$ after (a) as-reflowed, (b) 30, and (c) 365 days.

Fig. 12. The SEM images after the shear creep test with applied stress of $18.75 \mathrm{MPa}$ at $25^{\circ} \mathrm{C}$ and aging at $100^{\circ} \mathrm{C}$ for 2 months.

Fig. 13. The SEM images after the shear creep test with applied stress of $18.75 \mathrm{MPa}$ at $25^{\circ} \mathrm{C}$ and aging at $100^{\circ} \mathrm{C}$ for 1 year. 
Table captions

Table 1. Shear creep tests. 


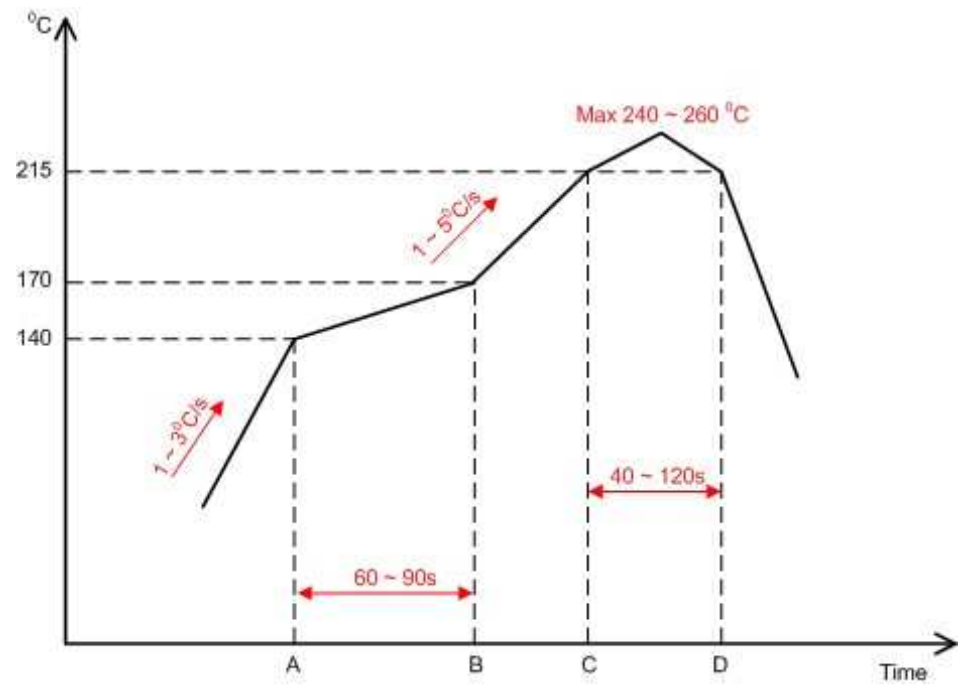

(a)

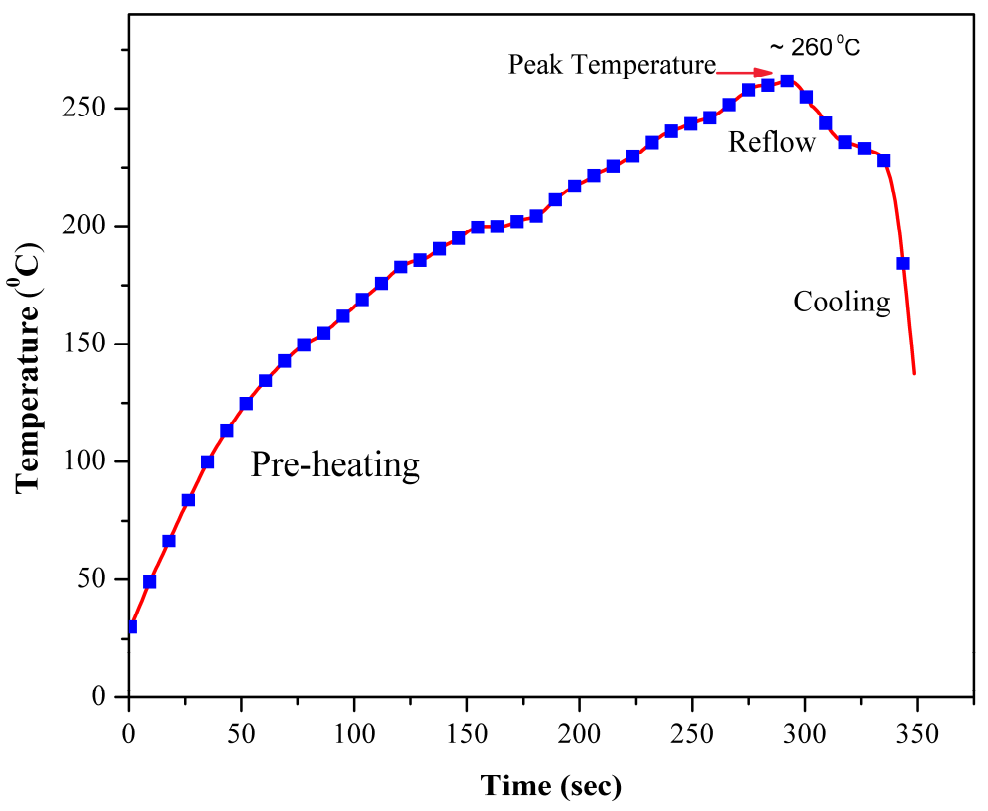

(b)

Fig. 1. 


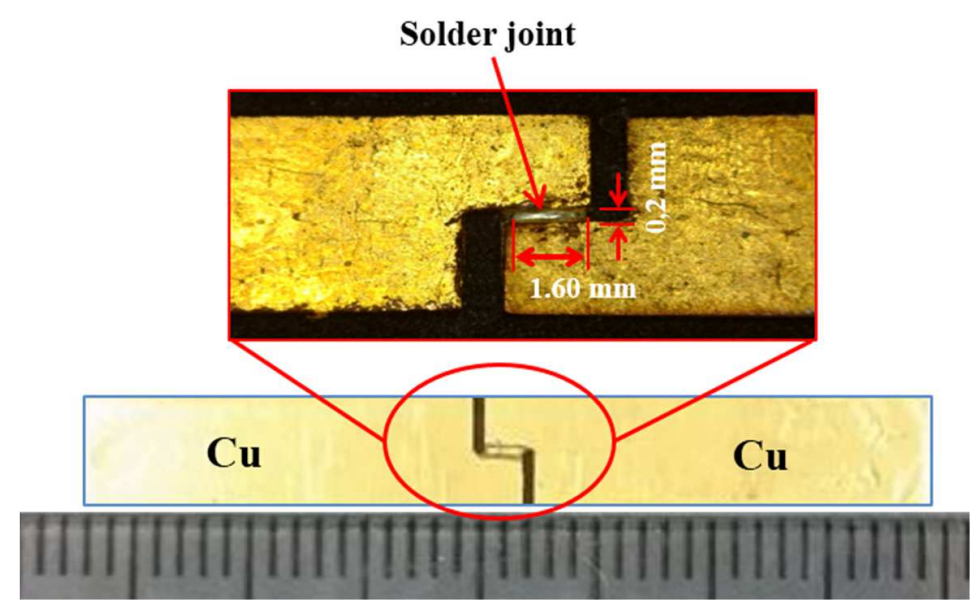

Fig. 2. 


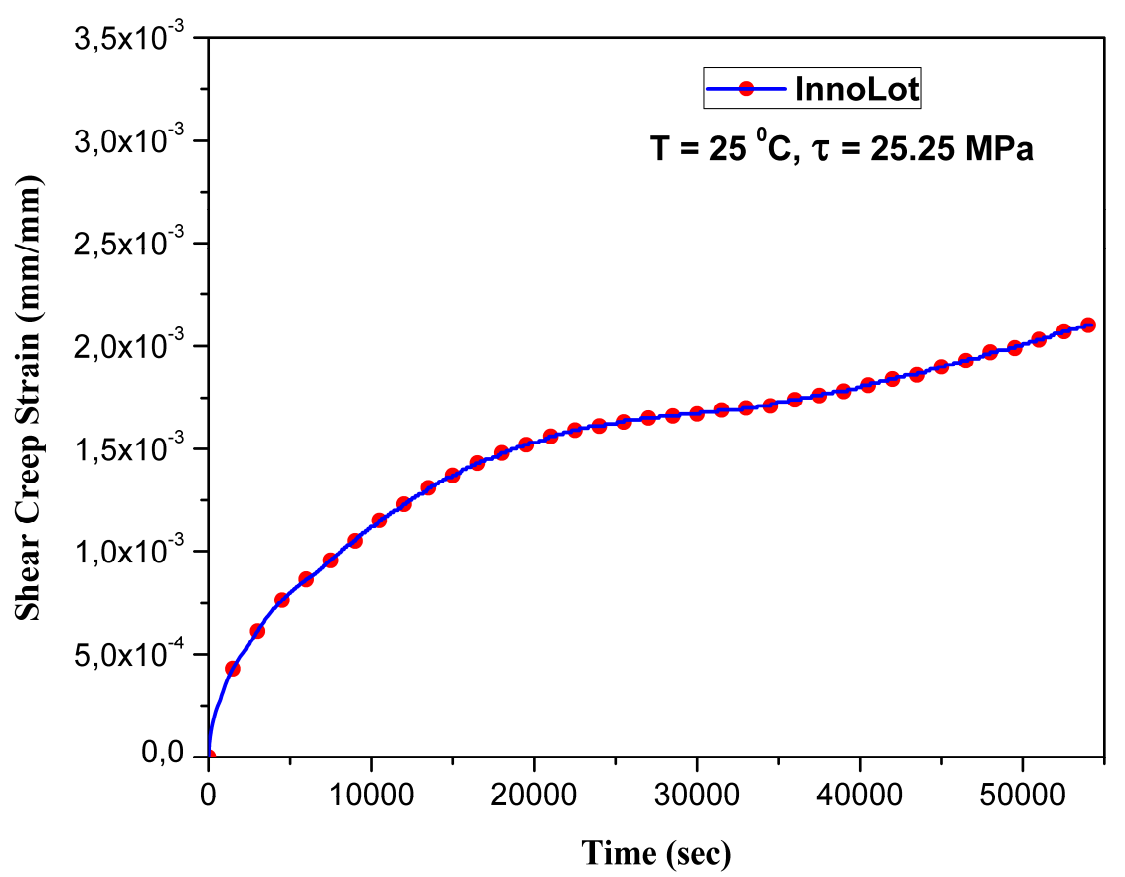

Fig. 3. 


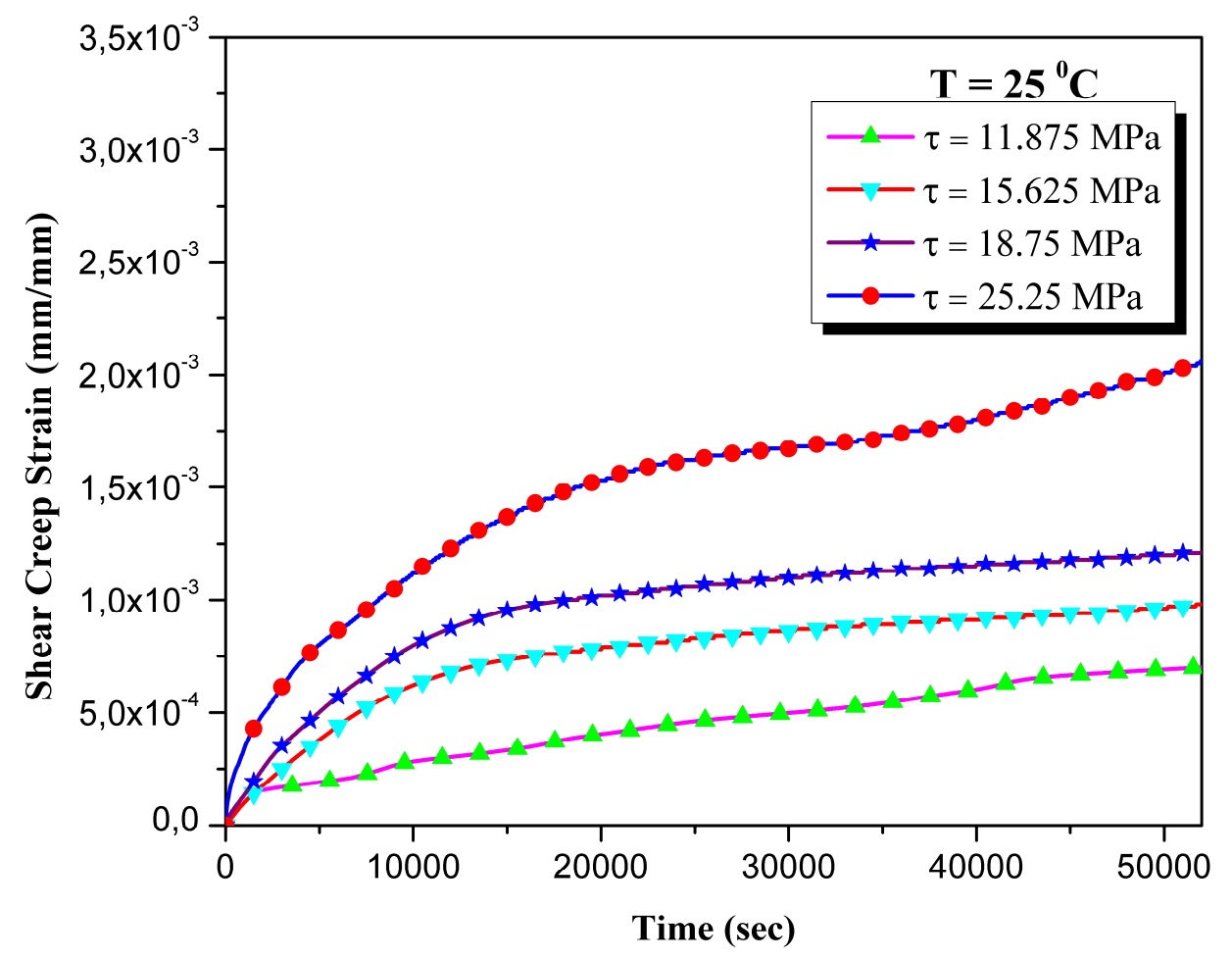

Fig. 4. 


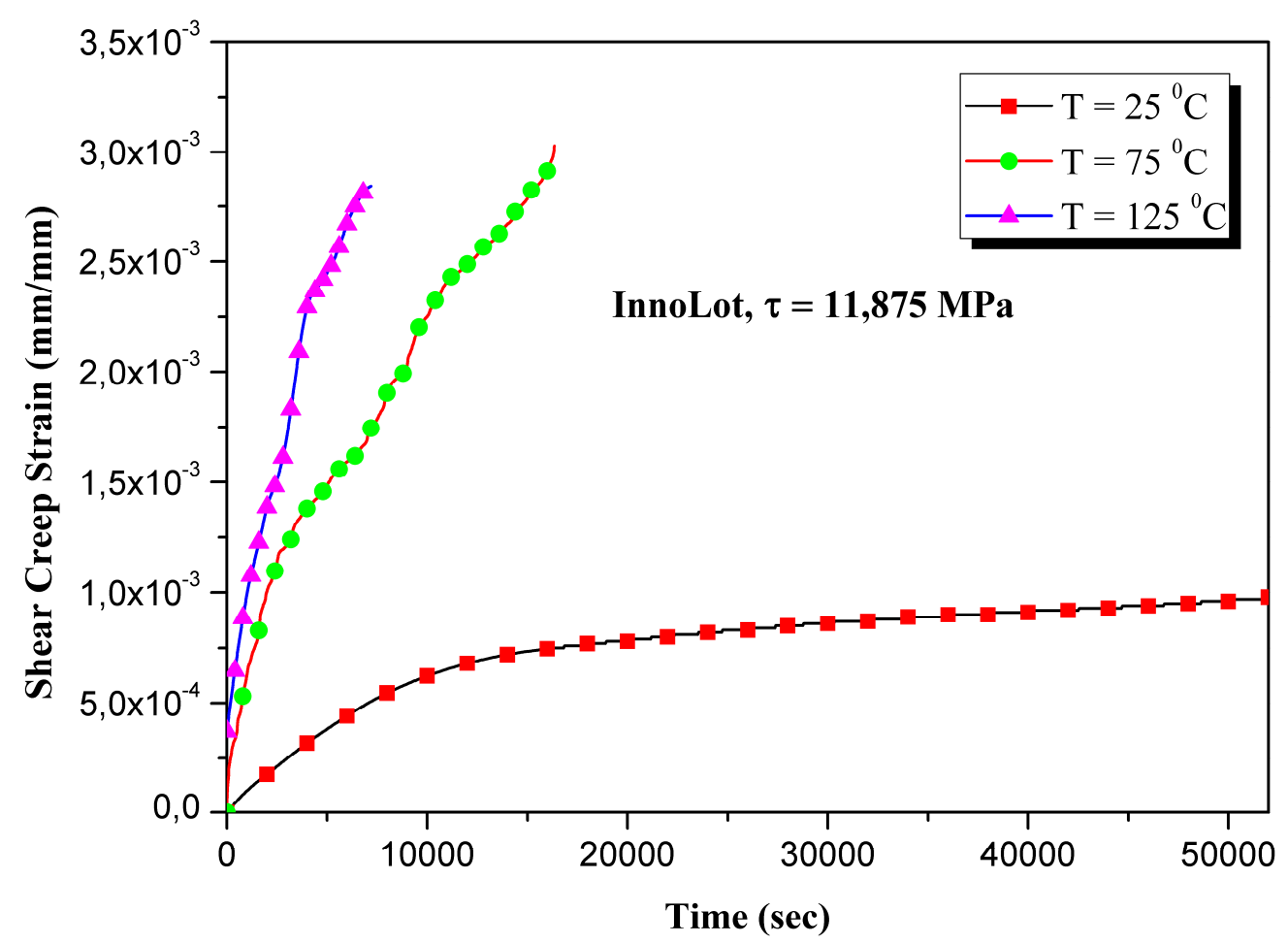

Fig. 5. 


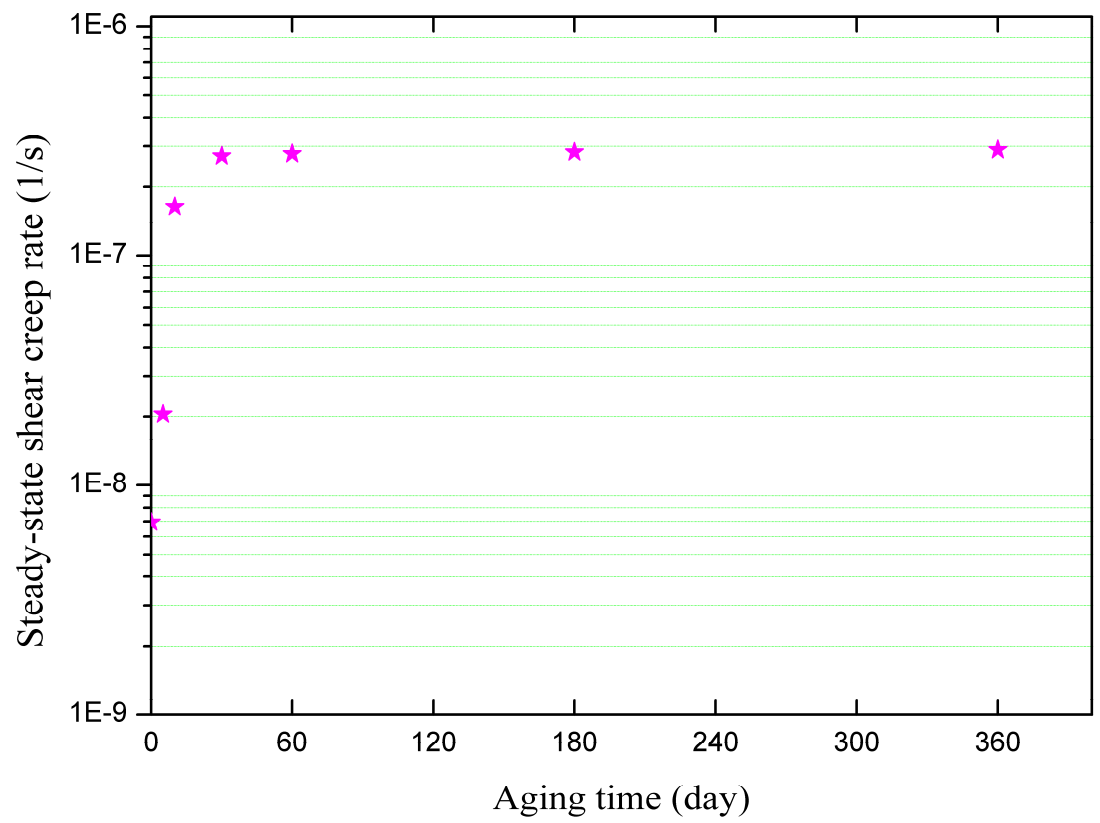

Fig. 6. 


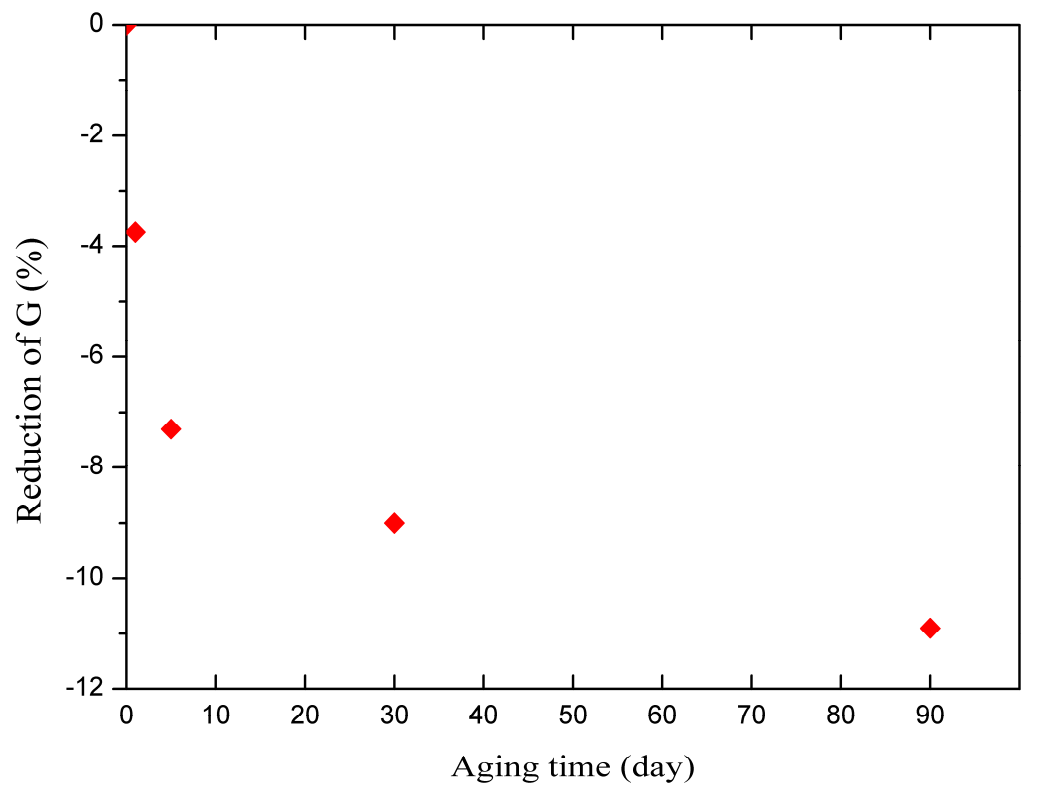

Fig. 7. 


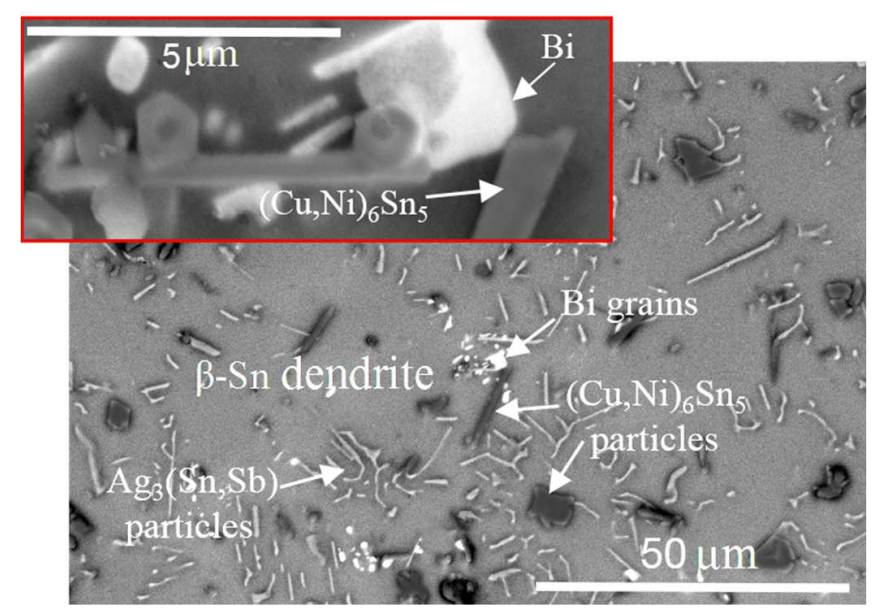

(a)

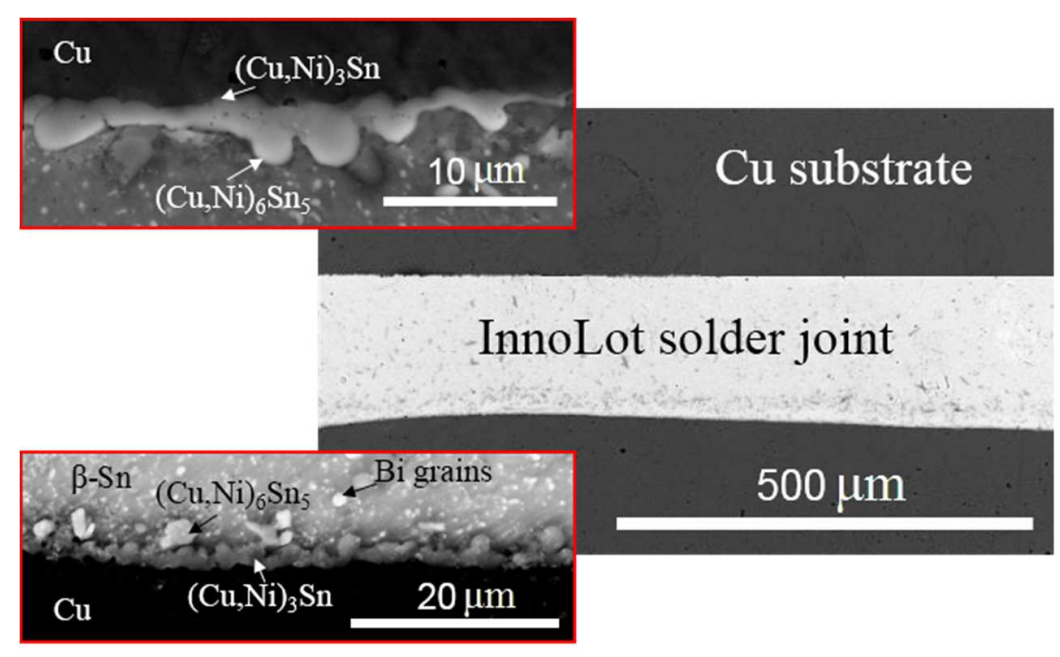

(b)

Fig. 8. 

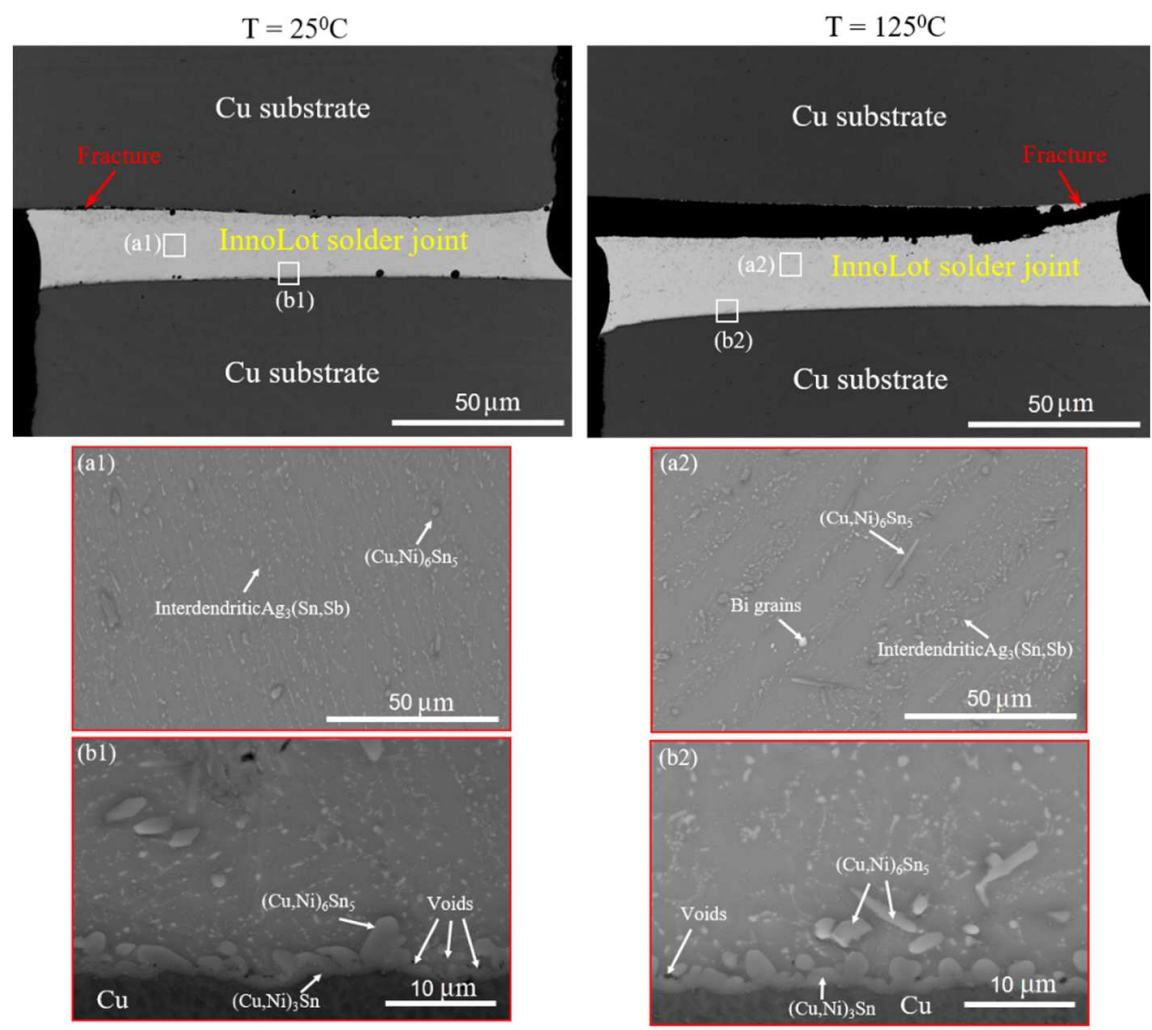

Fig. 9. 


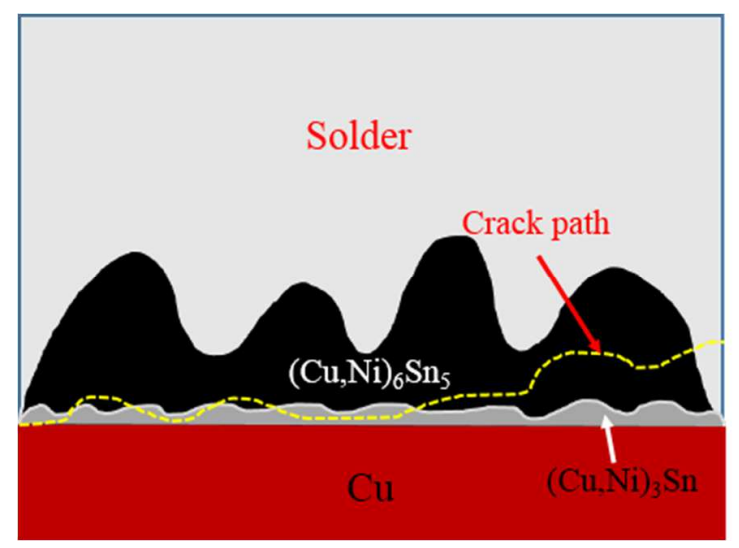

(a)

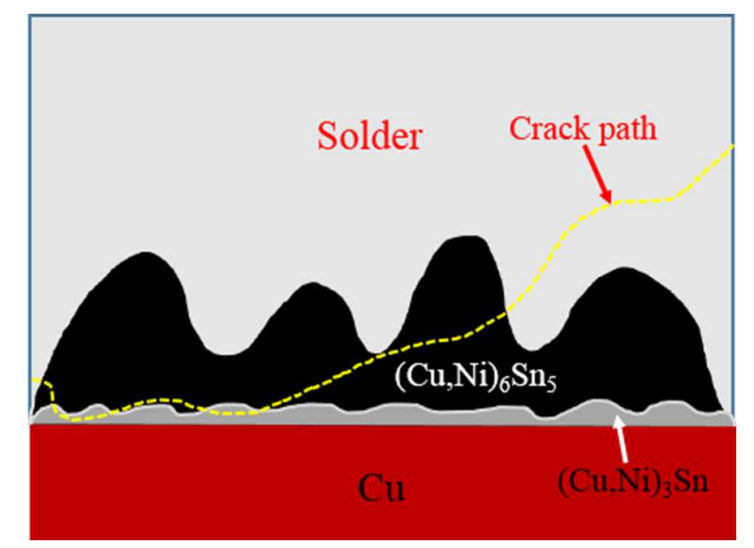

(b)

Fig. 10. 


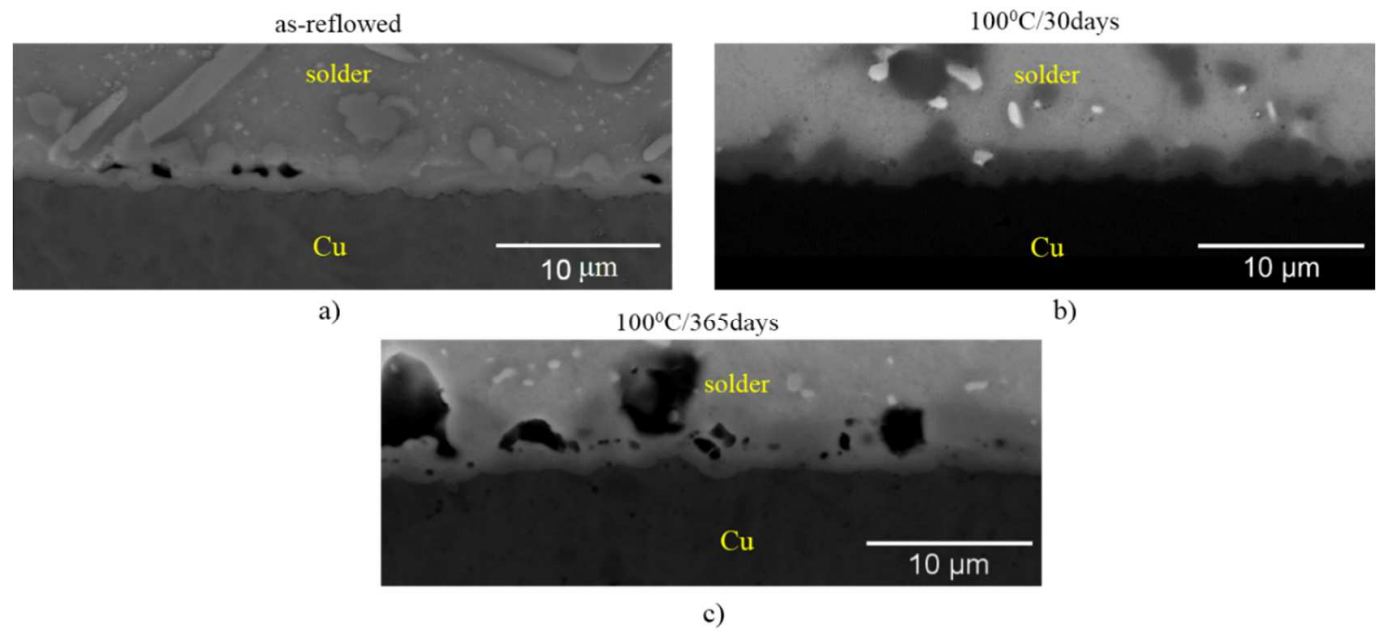

Fig. 11. 

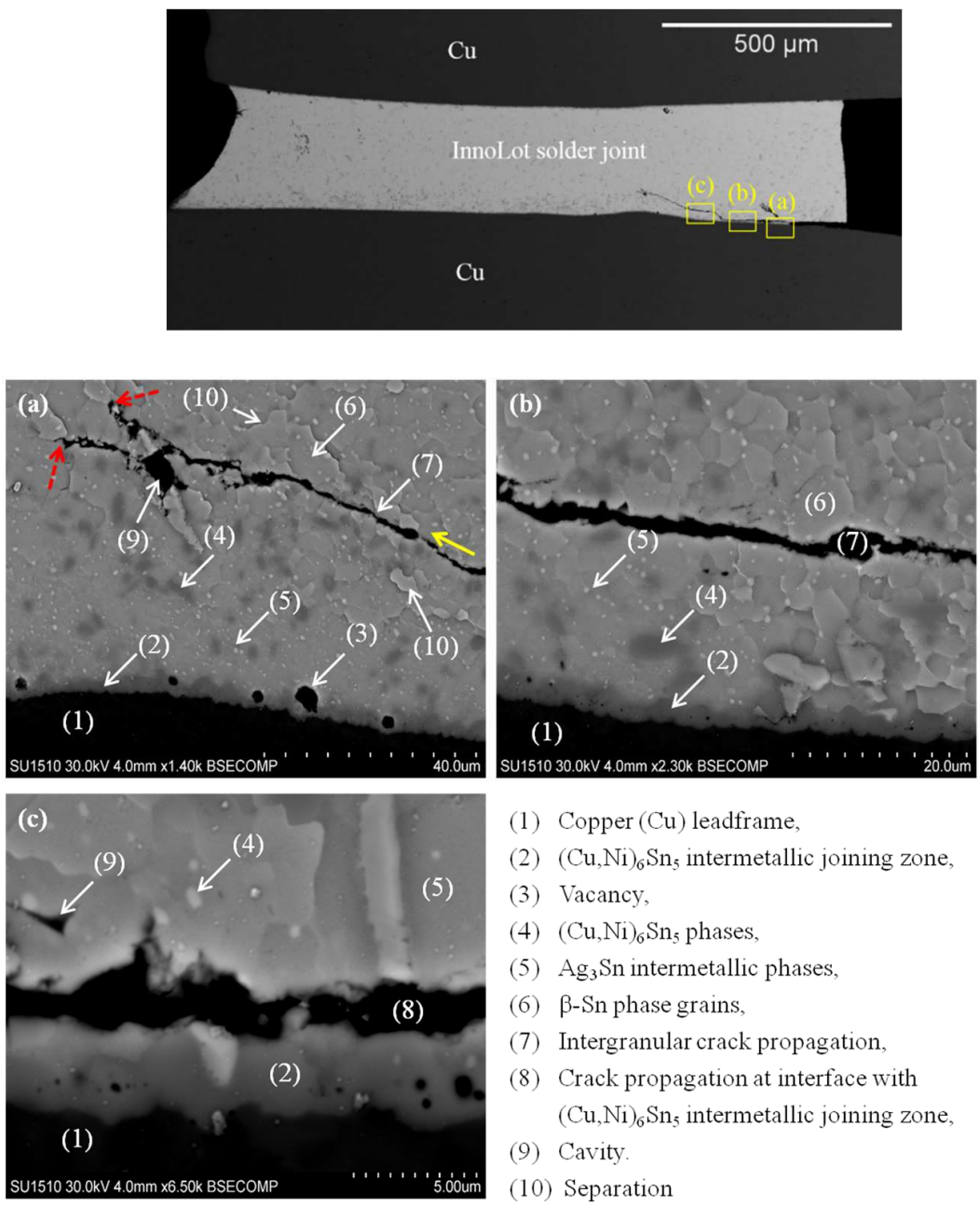

(1) Copper $(\mathrm{Cu})$ leadframe,

(2) $(\mathrm{Cu}, \mathrm{Ni})_{6} \mathrm{Sn}_{5}$ intermetallic joining zone,

(3) Vacancy

(4) $\left(\mathrm{Cu}, \mathrm{Ni}_{6} \mathrm{Sn}_{5}\right.$ phases,

(5) $\mathrm{Ag}_{3} \mathrm{Sn}$ intermetallic phases,

(6) $\beta$-Sn phase grains,

(7) Intergranular crack propagation,

(8) Crack propagation at interface with $(\mathrm{Cu}, \mathrm{Ni})_{6} \mathrm{Sn}_{5}$ intermetallic joining zone, (9) Cavity

(10) Separation

Fig. 12. 


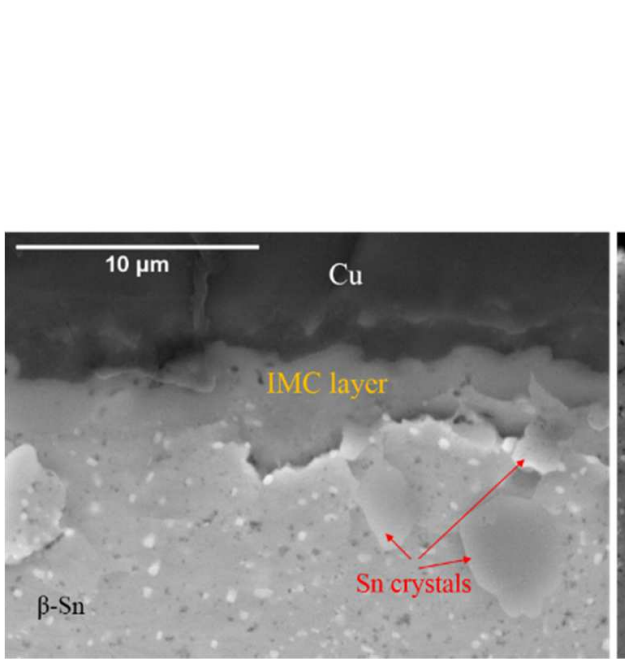

(a)
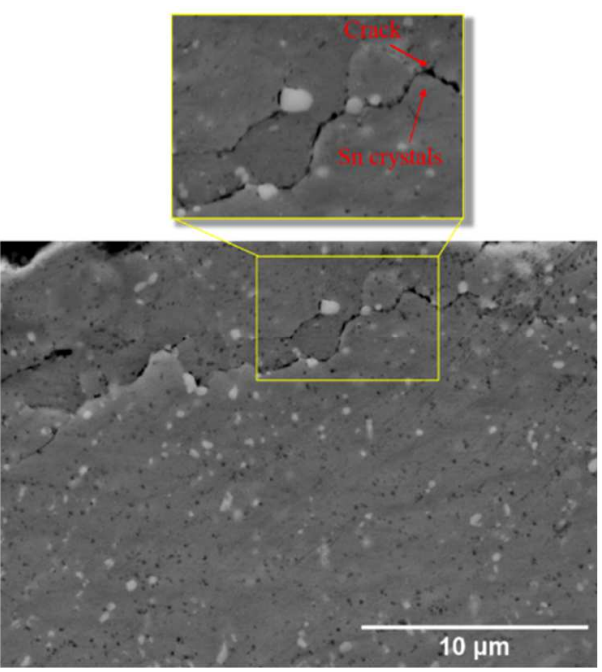

(b)

Fig. 13. 
Table 1.

\begin{tabular}{|c|c|c|c|c|c|}
\hline Solder Material & $\begin{array}{c}\text { Applied stress } \\
\text { (MPa) }\end{array}$ & 5.89 & 11.875 & 18.75 & 25.25 \\
\hline \multirow{3}{*}{ InnoLot } & Room temperature & $\checkmark$ & $\checkmark$ & $\checkmark$ & $\checkmark$ \\
\cline { 2 - 6 } & $75^{\circ} \mathrm{C}$ & $\checkmark$ & $\checkmark$ & $\checkmark$ & $\checkmark$ \\
\cline { 2 - 6 } & $125^{\circ} \mathrm{C}$ & $\checkmark$ & $\checkmark$ & $\checkmark$ & $\checkmark$ \\
\hline
\end{tabular}



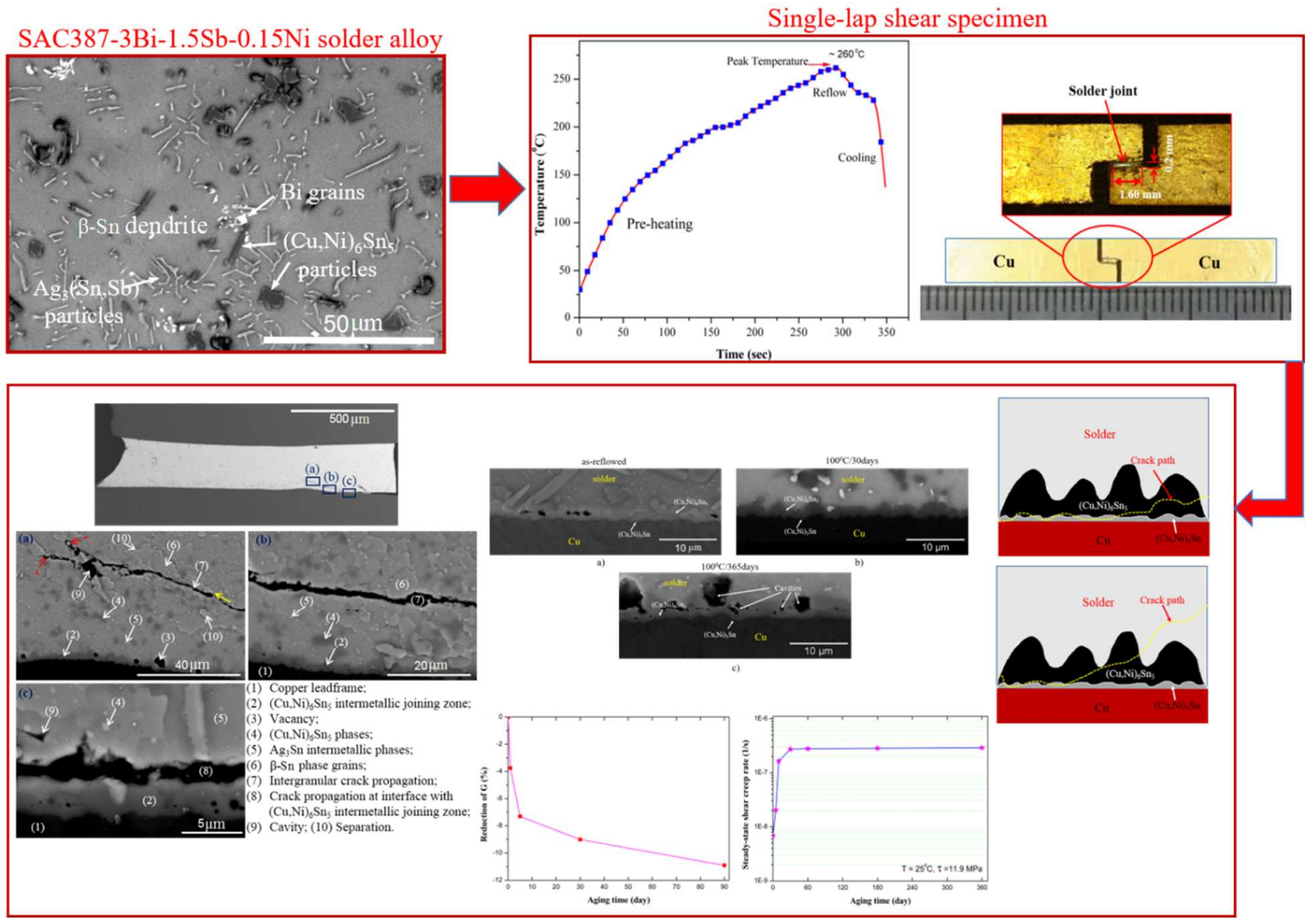